\title{
Granuloma eosinofílico da coluna vertebral cervical em criança
}

\author{
Rodrigo Moreira Faleiro ${ }^{1}$, Luanna Rocha Vieira Martins², Geraldo Vítor Cardoso Bicalho ${ }^{3}$ \\ Hospital Felício Rocho, Belo Horizonte, Minas Gerais, Brasil.
}

\section{RESUMO}

Granuloma eosinofílico (GE) refere-se à forma benigna e mais frequente de histiocitose de células de Langerhans. Trata-se de uma doença que acomete principalmente crianças e adolescentes, sendo rara a sua ocorrência em adultos. Constitui a forma localizada de proliferação de histiócitos em crânio e ossos longos. O acometimento vertebral é incomum, sendo a localização cervical a menos descrita. Neste artigo, é descrito um caso de uma criança de 7 anos de idade com GE na coluna vertebral cervical com compressão medular. A criança evoluiu com regressão dos sintomas após tratamento conservador, tendo permanecido assintomática ao longo de seguimento de dois anos.

\section{PALAVRAS-CHAVE}

Granuloma eosinófilo, compressão da medula espinal, doenças da coluna vertebral, histiocitose de células de Langerhans, criança.

\begin{abstract}
Eosinophilic granuloma of the cervical spine in children

Eosinophilic granuloma (EG) is a benign and more frequent form of Langerhans cell histiocytosis. Children and adolescent are mainly affected, being rare in adults. There is local proliferation of histiocytes in skull and long bones. Vertebral involvement is uncommon, especially at the cervical local. In this paper, we describe a case of a 7 years old child with EG in the cervical spine with spinal cord compression. The patient presented with regression of symptoms after conservative treatment and remained asymptomatic
\end{abstract} at the two years follow-up.

\section{KEYWORDS}

Eosinophilic granuloma, spinal cord compression, spinal diseases, Langerhans cells histiocytosis, child.

\section{Introdução}

Tumores ósseos primários envolvendo a coluna vertebral em crianças são raros. Quando ocorrem, geralmente se enquadram nos seguintes subtipos: granuloma eosinofílico, cordoma, osteoma, sarcoma de Ewing, condrossarcoma mesenquimal, osteossarcoma, osteoblastoma, cisto ósseo aneurismático, displasia fibrosa, fibroma, angiossarcoma e hemangioma. ${ }^{1} \mathrm{O}$ granuloma eosinofílico (GE) ocorre em 6,5\%-25\% desses casos. ${ }^{2,3}$

O GE representa $1 \%$ de todos os tumores ósseos. ${ }^{4}$ Acomete a coluna vertebral em $7 \%$ dos casos, ${ }^{4}$ sendo a região cervical menos afetada. ${ }^{5,6}$ Trata-se de uma doença benigna que ocorre principalmente em crianças e integra aproximadamente $75 \%{ }^{7}$ de um espectro de doenças conhecido como histiocitose de células de Langerhans, que também engloba a doença de Hand-Schüller-Christian (HSC) e a doença de Letterer-Siwe (LS). Essas três doenças possuem padrão histopatológico em comum constituído por células de Langerhans e eosinófilos.

A seguir, é descrito um caso de uma criança com GE na coluna vertebral cervical com compressão medular subjacente.

\section{Relato do caso}

Paciente de 7 anos, sexo masculino, natural de Nova Lima/MG, foi admitido com um histórico de quadro subagudo de cervicobraquialgia. Não havia histórico de trauma ou outras doenças. Procurou ortopedista, que prescreveu analgésicos e uso de colar cervical. Verificou-se melhora da irradiação, contudo houve persistência da dor cervical.

1 Chefe do Serviço de Neurocirurgia e Neurologia do Hospital João XXIII, neurocirurgião do Hospital Felício Rocho, Belo Horizonte, MG, Brasil.

2 Acadêmica de Medicina da Universidade Federal de Minas Gerais (UFMG), Belo Horizonte, MG, Brasil.

3 Residente de Neurocirurgia da Fundação Hospitalar do Estado de Minas Gerais (FHEMIG), Belo Horizonte, MG, Brasil. 
Realizaram-se raios X cervical e ressonância nuclear magnética (RNM), que revelaram a presença de vértebra plana (C-7) com compressão medular subjacente (Figuras 1 e 2).

A seguir, foi realizada biópsia por via cervical anterior, cuja análise anatomopatológica revelou a presença de numerosas células de Langerhans e grande número de eosinófilos (Figura 3).

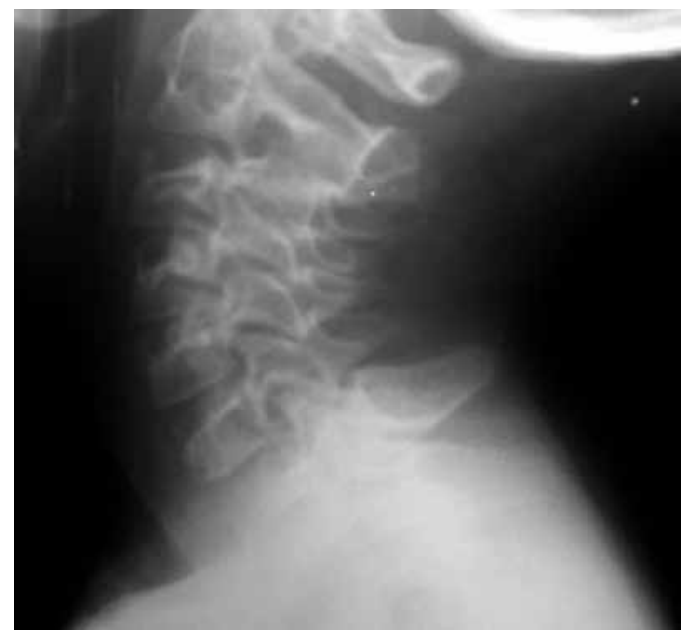

Figura 1 - Raio X da coluna vertebral cervical, obtido na admissão do paciente, revela vértebra plana em C-7.

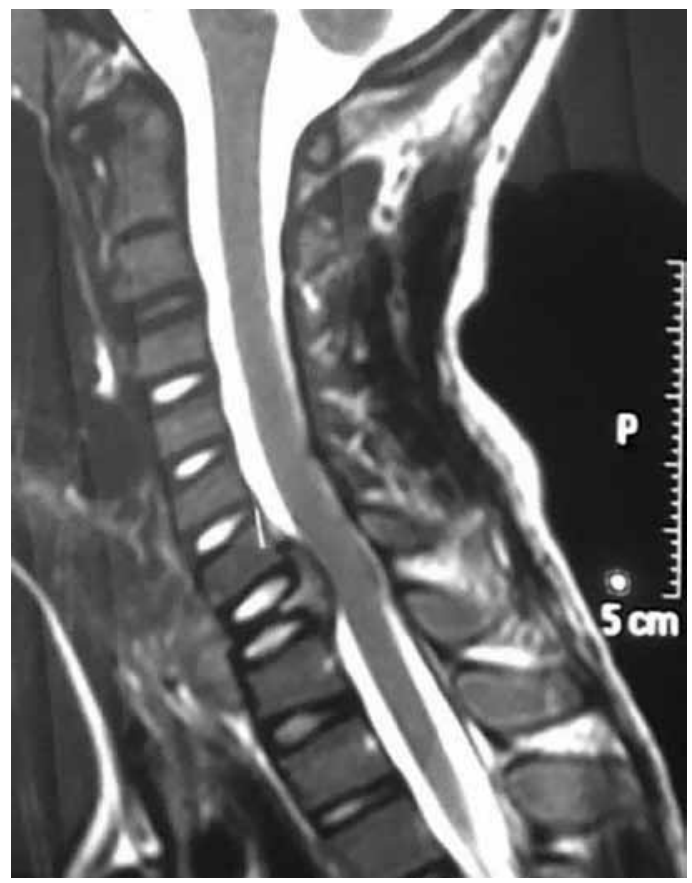

Figura 2 - RNM da coluna vertebral revela vértebra plana em C-7. Nesse nivel, houve colapso e desaparecimento do corpo da vértebra com preservação dos discos adjacentes. Nota-se compressão medular subjacente.
Como tratamento, optou-se pela conduta conservadora com uso de colar cervical (Miami-J) por três meses. $\mathrm{O}$ paciente também foi submetido à radioterapia. Após 45 dias, foi realizada nova RNM, que mostrou evolução com resolução quase total da massa tumoral e não havia mais compressão medular (Figura 4). Paciente estava assintomático nessa data apesar da permanência da vértebra plana.

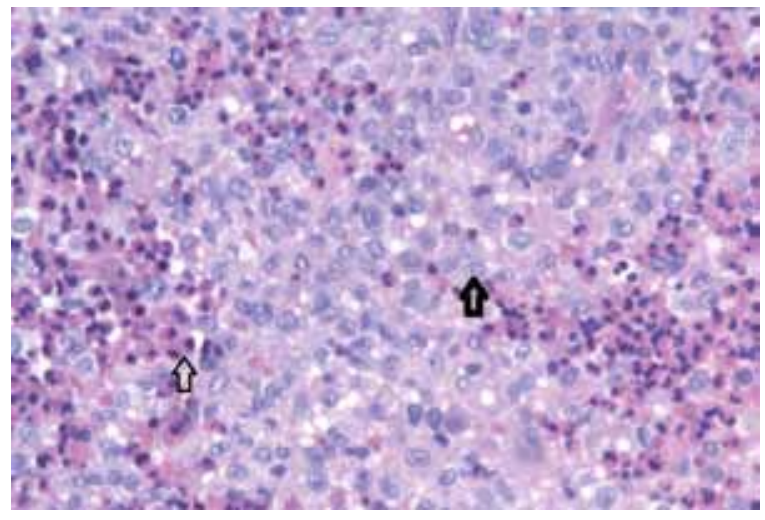

Figura 3 - Fotomicrografia preparada com coloração HeE (1.000x) mostra achados histológicos compostos por células de Langerhans (seta larga) e eosinófilos (seta estreita), características-padrão do granuloma eosinofílico.

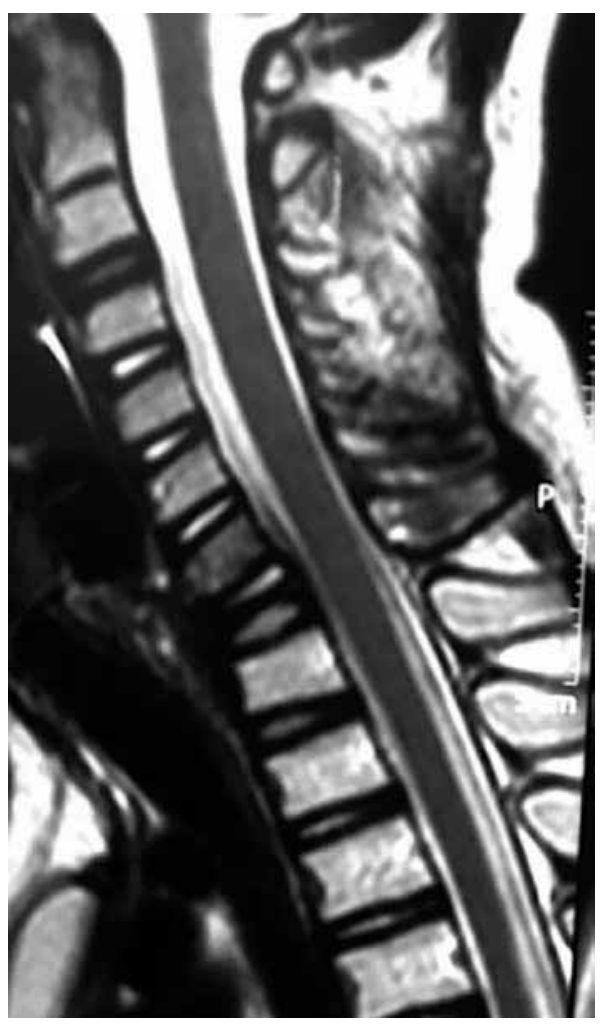

Figura 4 - RNM obtida após 45 dias do início do tratamento conservador evidencia evolução com resolução quase total da massa tumoral. 
Após três meses de colar cervical, foi realizada prova funcional. Apesar da permanência da vértebra plana, os resultados foram normais, não apresentando luxações. Optou-se pelo uso do colar cervical por mais dois meses e houve liberação do paciente para atividades físicas.

\section{Discussão}

O GE é reconhecido como uma entidade patológica desde $1940 .{ }^{8,9}$ Juntamente com a LS e o HSC, integra um espectro de doenças denominado histiocitose de células de Langerhans, anteriormente denominado histiocitose X. Apesar de variar do ponto de vista clínico, essas doenças possuem padrão histológico em comum constituído por células de Langerhans. Essas células integram o sistema reticuloendotelial e atuam na resposta imune cutânea como apresentadoras de antígenos. ${ }^{10}$

A LS afeta ossos, vísceras e o sistema reticuloendotelial, possuindo curso agudo e fulminante. ${ }^{4}$ A HSC tende a ter um curso mais crônico ${ }^{4} \mathrm{e}$ consiste classicamente na tríade composta por diabetes insipidus, exoftalmo e lesões ósseas. ${ }^{11} \mathrm{O}$ GE, por sua vez, representa a forma benigna e mais frequente de histiocitose de células de Langerhans. Consiste em lesão osteolítica unifocal ou multifocal, ${ }^{11}$ acometendo a coluna vertebral em $7 \%$ dos casos. ${ }^{4}$

Quando o GE acomete a coluna vertebral, a localização mais comum é a torácica (54\%), seguida pela lombar (35\%). ${ }^{12,13}$ A região cervical é a menos afetada (11\%). ${ }^{5,6}$ Em 1999, Duarte-Silva et al. relataram o sexto caso descrito em literatura de GE com compressão medular cervical. ${ }^{7}$

A queixa mais comum do GE é a dor local e rigidez; ${ }^{14}$ no entanto, os pacientes podem ser assintomáticos, podendo desenvolver os sintomas após traumas leves que impliquem fraturas patológicas. ${ }^{6}$ Além disso, déficits sensitivos e/ou motores podem ocorrer. ${ }^{7}$

Radiograficamente, a alteração mais precoce é a destruição do centro da vértebra. ${ }^{4}$ Quando o colapso do corpo da vértebra progride para a aparência típica de vértebra plana com os discos intervertebrais intactos, o diagnóstico de GE é quase certo. ${ }^{12} \mathrm{Em}$ crianças, o colapso do corpo vertebral (vértebra plana) é geralmente considerado patognomônico de GE. No entanto, o GE deve ser diferenciado de outras condições como infecções bacterianas ou fúngicas e de certos tumores, como neuroblastoma, sarcoma de Ewing, cordoma e leucemia. ${ }^{15,16}$ Para fazer o diagnóstico diferencial, é necessária biópsia da lesão. No entanto, para alguns autores, lesões típicas não requerem biópsia e podem ser seguramente acompanhadas com exames de imagem. ${ }^{6}$

No que se refere ao tratamento do GE, os objetivos a serem alcançados são estabilidade da coluna vertebral e preservação das funções neurológicas. ${ }^{4} \mathrm{O}$ tratamento pode ser conservador, cirúrgico, radioterápico ou quimioterápico. Além disso, pode ocorrer cura sem tratamento por causa do alto potencial de crescimento e regeneração do tecido sadio. ${ }^{5}$

O tratamento conservador composto por repouso e imobilização é a terapia de escolha para pacientes sem déficits neurológicos, considerando a natureza autolimitante da lesão solitária e o alto potencial de regeneração óssea em pacientes jovens. ${ }^{6,17,18}$

O tratamento cirúrgico é indicado quando a lesão compromete a estabilidade da coluna vertebral ou está associada com déficits neurológicos e quando se requer uma biópsia para fazer diagnóstico diferencial. ${ }^{19-22}$

No passado, recomendava-se radioterapia em baixas doses (400 a $1.500 \mathrm{rads}) ;^{15,19}$ no entanto, a radioterapia é considerada atualmente desnecessária por muitos autores. ${ }^{23,24}$ Contudo, alguns autores defendem que imobilização associada com radioterapia fornece um tratamento adequado para pacientes com déficits neurológicos. ${ }^{19}$

Por fim, a quimioterapia é justificada apenas em casos de lesões múltiplas e quando os tratamentos cirúrgico e radioterápico falharam. ${ }^{6,17}$

Este relato demonstrou melhora do quadro patológico após imobilização e radioterapia, não ocorrendo instabilidade da coluna. Em seguimento de dois anos, a criança mantém-se assintomática e realiza atividades físicas.

\section{Referências}

1. Fenoy AJ, Greenlee JD, Menezes AH, Donovan KA, Sato $\mathrm{Y}$, Hitchon PW, et al. Primary bone tumors of the spine in children. J Neurosurg. 2006;105(Suppl 4):252-60.

2. Bunch WH. Orthopedic and rehabilitation aspects of eosinophilic granuloma. Am J Pediatr Hematol Oncol. 1981;3(2):151-6.

3. Mirra JM, Picci P. Bone tumors: clinical, radiologic, and pathologic correlations. Pliladhelpia: Lea e Febiger; 1989.

4. Sweasey TA, Dauser RC. Eosinophilic granuloma of the cervicothoracic junction. Case report. J Neurosurg. 1989;71(6):942-4.

5. Maggi G, de Sanctis N, Aliberti F, Nunziata Rega A. Eosinophilic granuloma of $\mathrm{C} 4$ causing spinal cord compression. Childs Nerv Syst. 1996;12(10):630-2.

6. Osenbach RK, Youngblood LA, Menezes AH. Atlanto-axial instability secondary to solitary eosinophilic granuloma of C2 in a 12-year-old girl. J Spinal Disord. 1990;3(4):408-12.

7. Duarte-Silva EB, Noujaim J el-K, Carnevale F. Cervical spine cord compression by eosinophilic granuloma. Case report. Arq Neuropsiquiatr. 1999;57(2B):498-503.

8. Lichtenstein L, Jeffe HL. Eosinophilic granuloma of bone: with report of a case. Am J Pathol. 1940;16(5):595-604.

9. Otani S, Ehrlich JC. Solitary granuloma of bone: simulating primary neoplasm. Am J Pathol. 1940;16(4):479-90. 
10. Savaşan S. An enigmatic disease: childhood Langerhans cell histiocytosis in 2005. Int J Dermatol. 2006;45(3):182-8.

11. Davidson L, McComb JG, Bowen I, Krieger MD. Craniospinal Langerhans cell histiocytosis in children: 30 years' experience at a single institution. $J$ Neurosurg Pediatr. 2008;1(3):187-95.

12. Krüger L, Schmitt E. Solitary involvement of the fourth thoracic vertebral body with eosinophilic granuloma and development of incomplete paraparesis. Eur Spine J. 1995;4(5):313-6.

13. Wongchanchailert $\mathrm{M}$, Laosombat $\mathrm{V}$, Phuenpathom $\mathrm{N}$, Mitarnan W. Langerhans cell histiocytosis of the spinal cord: a case report. J Med Assoc Thai. 1990;73(12):697-703.

14. Bilge T, Barut S, Yaymaci Y, Alatli C. Solitary eosinophilic granuloma of the lumbar spine in an adult. Case report. Paraplegia. 1995;33(8):485-7.

15. Davidson RI, Shillito J Jr. Eosinophilic granuloma of the cervical spine in children. Pediatrics. 1970;45(5):746-52.

16. Nesbit ME, Kieffer S, D'Angio GJ. Reconstitution of vertebral height in histiocytosis $X$ : a long-term follow-up. J Bone Joint Surg Am. 1969;51(7):1360-8.

17. Dickinson LD, Farhat SM. Eosinophilic granuloma of the cervical spine. A case report and review of the literature. Surg Neurol. 1991;35(1):57-63.

18. Kiepurska $A$. [Long-term results of treating histiocytosis $X$ of the spine]. Chir Narzadow Ruchu Ortop Pol. 1991;56(13):17-21.
19. Green NE, Robertson WW Jr, Kilroy AW. Eosinophilic granuloma of the spine with associated neural deficit. Report of three cases. J Bone Joint Surg Am. 1980;62(7):1198-202.

20. Sherk $\mathrm{HH}$, Nicholson JT, Nixon JE. Vertebra plana and eosinophilic granuloma of the cervical spine in children. Spine (Phila Pa 1976). 1978;3(2):116-21.

21. Villas C, Martínez-Peric R, Barrios RH, Beguiristain JL. Eosinophilic granuloma of the spine with and without vertebra plana: long-term follow-up of six cases. J Spinal Disord. 1993;6(3):260-8.

22. Yabsley $\mathrm{RH}$, Harris WR. Solitary eosinophilic granuloma of a vertebral body causing paraplegia. Report of a case. J Bone Joint Surg Am. 1966;48(8):1570-4.

23. Mickelson MR, Bonfiglio M. Eosinophilic granuloma and its variations. Orthop Clin North Am. 1977;8(4):933-45.

24. Seimon LP. Eosinophil granuloma of the spine. J Pediatr Orthop. 1981;1(4):371-6.

Endereco para correspondência

Rodrigo Moreira Faleiro

Rua Caraça, 518, ap. 201, Serra

30220-260 - Belo Horizonte, MG

Telefone: (31) 9970-7676

E-mail: r.m.faleiro@hotmail.com 